\title{
Association between funcional vision, balance and fear of falling in older adults with cataracts
}

\author{
Associaçãoetrevis̃̃ofuniand, equilibrioemedbdecir emidbsoscanctarda
}

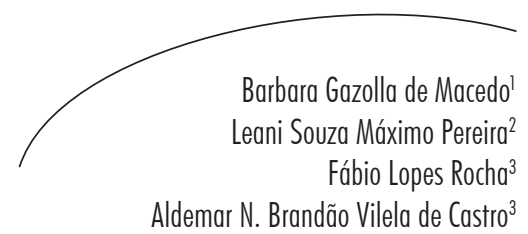

Resumo

Background: Cataract is the most common visual problem in the elderly population. It affects mobility and balance as it reduces the perception of the edges of steps and sidewalks, as well as altering depth perception of the ground. It has been shown that poor performances in tests of distant contrast sensitivity and depth perception were independent predictors of increased sway in older people. Objectives: this study aimed to verify the association between functional balance, visual functioning and fear of falling in older adults with cataracts. Method: it was a transversal observational study in which 139 elderly patients (aged $71.4 \pm 6.2$ years) participated. Their vision was Key words: Aged. Cataract. Vision, Ocular. Fear. assessed using the Snellen chart and the Visual Function Questionnaire (VFQ). The Accidental Falls. Berg Balance Scale was used to assessment functional balance, the Timed Up and Go to assess mobility and Falls Efficacy Scale International (FES-I) to assess the fear of falling. Results: Statistically significant associations were found in the bivariate analyses between balance (Berg) and the variables: visual acuity (Kruskal-Wallis, $\mathrm{p}=0.006)$; TUG (Pearson=-0.528, $\mathrm{p}=0.000)$ and FES-I, (Pearson=-0.355, $\mathrm{p}=0.000$ ). Analysis of the multivariate regression between the BBS and the variables gender, age, visual acuity, VFQ, FES-I-Brazil and number of medicines used. The regression analysis explained a $32.8 \%$ variance in the dependent variable (Berg). Conclusions: visual deficits in the elderly can cause alterations in balance and mobility, contributing to a subsequent fear of falling.

\footnotetext{
Centro Universitário de Belo Horizonte e Instituto da Previdência dos Servidores do Estado de Minas Gerais. Unidade de Fisioterapia, Departamento de Reumatologia e Reabilitação Física. Belo Horizonte, MG, Brasil.

2 Universidade Federal de Minas Gerais.Unidade de Fisioterapia, Departamento de Ciências da Reabilitação. Belo Horizonte, MG, Brasil.

3 Instituto da Previdência dos Servidores do Estado de Minas Gerais. Unidade e Departamento de Psiquiatria e Oftalmologia. Belo Horizonte, MG, Brasil.
} 


\section{Abstract}

Contextualização: catarata é o problema visual mais comum na população idosa. Afeta a mobilidade e o equilíbrio, uma vez que reduz a percepção das bordas dos degraus e calçadas e a percepção de profundidade do solo. Estudos mostraram que performance ruim em testes de sensibilidade ao constraste à distância e de percepção de profundidade foram preditores independentes de aumento da oscilação corporal em idosos. Objetivos: o objetivo do estudo foi verificar a associação entre equilíbrio funcional, visão funcional e medo de cair em idosos com catarata. Método: trata-se de um estudo transversal, observacional com 139 idosos (71,4 \pm 6.2 anos). A visão foi avaliada pelo quadro de Snellen e pelo Visual Function Questionnaire (VFQ). A escala de Berg (BBS) foi usada para avaliar equilíbrio funcional, o Timed $U p$ and Go para avaliar mobilidade e o medo de cair pela Falls Efficacy Scale International (FES-I Brazil). Resultados: encontraram-se associações significativas nas análises bivariadas entre equilíbrio e acuidade visual (Kruskal-Wallis, $\mathrm{p}=0,006$ ); TUG (Pearson=-0,528, $\mathrm{p}=0,000$ ) e FES-I, (Pearson=-0,355, $\mathrm{p}=0,000)$. A análise de regressão multivariada entre a BBS e as variáveis como sexo, idade, acuidade visual, VFQ, FES-I Brasil e número de medicamentos foi realizada. A análise de regressão foi capaz de explicar 32,8\% da variância na variável dependente (Berg). Conclusão: déficits visuais em idosos podem ocasionar alterações no equilíbrio ou na mobilidade, desencadeando o medo de cair.
Palavras-chave: Idoso. Catarata. Visão Ocular. Medo. Acidentes por Quedas.

\section{INTRODUCTION}

The substitution of infectious disease by chronic-degenerative disease is a reality which brings an increase in capacity, dependence and loss of autonomy among the elderly. Functional incapacities due to cerebral vascular accidents, from chronic obstructive pulmonary disease, osteoarticular disease, dementia and sensorial deficit, such as auditory and visual deficits, can lead to a state of functional dependence for those individuals who grow old. ${ }^{1,2}$

One of the first systems to suffer the impact of the physiological aging process is the sensory system, especially vision. Functional alterations of vision are frequent, i.e., decrease in visual acuity and of the peripheral field, contrast sensitivity, color discrimination, ability to recover after exposure to a glare, dark adaptation and depth perception..$^{3-5}$

Cataract is the most common visual problem in the elderly population. ${ }^{6}$ It affects mobility and balance as it reduces the perception of the edges of steps and sidewalks, as well as altering depth perception of the ground. ${ }^{7}$ It has been shown that poor performances in tests of distant contrast sensitivity and depth perception were independent predictors of increased sway in older people., ${ }^{78}$

The loss or reduction of vision can interfere with the equilibrium of the elderly, since it affects the labyrinth-vestibule system by feedback from the visual system. The ability to keep balance and postural control is important for the adequate performance of functional tasks and daily life. The deterioration of balance with age is well defined in the literature. Elderly patients with balance deficit are more prone to falls and their consequences. $^{7-12}$

Fallsrepresentabigsocialproblemthrough their relationship with physical decline, psychosocial consequences (fear of falling, depression, anxiety, among others). The fear of falling, at present, has been defined as low self-efficacy or selfconfidence in one's own equilibrium to avoid falls, causing limitations in the performance of the daily activities, with negative impact on the quality of life. ${ }^{13-15}$ Consequently, elderly people with low visual acuity tend to diminish their basic, instrumental daily life activities. ${ }^{9-11}$ The presence of visual alterations, whether the problem is with acuity, contrast, glare sensitivity or depth perception, is reported as a factor that 
increases the morbidity and the mortality in older patients. The difficulty in performing daily tasks, such as taking walks, getting up from and lying down on the bed, getting up from and sitting on chairs, is also reported by older patients with visual alterations. ${ }^{16,17}$

This study aimed to verify the association between functional balance, visual functioning and fear of falling in older adults with cataracts.

\section{MATERIALS AND METHODS}

\section{Sample}

This was a cross-sectional observational study, comprising 139 elderly outpatients with a recommendation for cataract surgery from an ophthalmological clinic. It was approved by the Ethics in Research Committee, n. 218/06.

The following criteria of inclusion were used: age 60 years or more, diagnosis of cataract, and ability for independent walking without crutches. Patients who had any of the following were excluded: lack of independence for walking, limping, neurological disease, recently post-operative, rheumatic disease, active orthopedics, algic complaints, weakness of the inferior members, previous ophthalmological surgery or glaucoma.

\section{Instruments and procedures for data collection}

The tests were performed at the ophthalmological clinic, by two physical therapists who had been previously trained in a pilot study from October 2006 to July 2007.

In order to characterize the sample, the elderly answered a socio-demographic clinical questionnaire (gender, age, schooling, associated disease, use of medication, history of falling, presence of fear of falling, practice of physical activity, among others).

The functional balance of the elderly was assessed with the Berg Scale (BBS), which presents 14 common tasks for the performance of daily activities. ${ }^{18}$ The Timed Up and Go (TUG) test was performed to evaluate the functional mobility of the elderly. ${ }^{19}$ The Visual Function Questionnaire (VFQ) assesses both life quality and visual function. ${ }^{20}$ The fear of falling among the elderly was assessed using the Falls Efficacy Scale International (FES-I) ${ }^{21}$ The scale presents questions about the preoccupation with falling associated with 16 different activities of daily life. Visual acuity was measured by the ophthalmologist using the Snellen chart. This data was collected on the patients' medical charts.

\section{Statistical Analysis}

Descriptive analysis was used to characterize the sample. The other variables were analyzed using the following statistical tests: Kruskal-Wallis and Mann-Whitney (BBS x visual acuity; BBS x gender); Spearman (BBS x age); Pearson (BBS x TUG, FES-I-Brazil, and VFQ). The statistical program used was SPSS - Statistical Package for the Social Sciences, version 12, installed on Windows, and having established $\alpha=0.05$. Nonparametric tests were used as the dependent variable did not follow normal distribution ( $\mathrm{p}<$ 0.001; Shapiro-Wilk normality test).

To explore the nature of the relations between the BBS and the other variables (gender, age, visual function, FES-I-Brazil and number of medicines), a multivariate regression analysis was performed. The stepwise method was used.

Measurements of visual acuity were classified according to the following categories: no visual deficit $(\geq 0.5)$, light visual deficit ( 0.5 to $\geq 0.3$ ), moderate $(0.3$ to $\geq 0.1)$ and severe $(<0.1)$, according to Lee et al. (2003). In order to analyze the association (Kruskal-Wallis), measurement of visual acuity of the best eye was used. ${ }^{12}$

\section{RESULTS}

One hundred and thirty nine elderly patients $(71.4 \pm 6.2$ years old) with cataracts, the majority of whom $(58.2 \%)$ having received a diagnosis within the last year, participated. Of these, 
cataracts in both eyes represented $71.2 \%$ of the sample; right eye only was $13.7 \%$ and left eye only was $15.1 \%$. The practice of physical activity was reported by $35.3 \%$ of the elderly with cataracts, $87.5 \%$ performed physical activity three or more times a week and the most common activity was walking (24\%). A maximum of two daily medicines was taken by $61.8 \%$ of the elderly. The performance of the elderly in the assessment tools BBS (median=53.0), FES-I (average $=24.1 \pm 6.8$ ), VFQ (77.7 \pm 15.9$)$ and TUG (11.6 \pm 3.0$)$ are presented in table 1 .

Table 1 - Performance of the elderly on the assessment tools: BERG, FES-I, VFQ e o TUG. Belo Horizonte, MG, 2007. ( $\mathrm{N}=139)$

\begin{tabular}{|c|c|c|c|c|c|c|c|c|}
\hline \multirow{2}{*}{ Variable } & \multicolumn{2}{|c|}{ Valid observations } & \multirow{2}{*}{ Average } & \multirow{2}{*}{$\begin{array}{l}\text { Standard } \\
\text { Deviation }\end{array}$} & \multirow{2}{*}{ C.V. } & \multirow{2}{*}{ Median } & \multirow{2}{*}{ Min. } & \multirow{2}{*}{ Max } \\
\hline & $\mathrm{N}$ & $\%$ & & & & & & \\
\hline $\begin{array}{l}\text { TUG } \\
\text { 1st measurement }\end{array}$ & 139 & 100.0 & 11.6 & 3.0 & 26.2 & 11.0 & 6.9 & 30.7 \\
\hline VFQ total score & 139 & 100.0 & 77.7 & 15.9 & 20.4 & 82.0 & 23.9 & 99.0 \\
\hline FES-I total score & 139 & 100.0 & 24.1 & 6.8 & 28.1 & 22.0 & 16.0 & 48.0 \\
\hline BERG total score & 139 & 100.0 & 52.2 & 3.4 & 6.6 & 53.0 & 38.0 & 56.0 \\
\hline
\end{tabular}

As to the performance of the elderly in the FES-I-Brazil, the most commonly reported activities as causing preoccupation with falling were the following: 11 - walking on a slippery surface, such as a wet floor (92.1\%); 14 - walking on a irregular surface, with stones and holes $(75.5 \%) ; 07$ - climbing or descending stairs $(66.2 \%) ; 15$ - climbing or descending a hill (54\%); 04 - taking a bath (45.3\%).

Analysis of the association of the performance of the elderly on the $B B S$, with gender and age

Women presented the worst performance on the BBS with lower averages and mediums, when compared to men (female gender: average $51.4 \pm 3.6$ e medium $=52.0$; male gender: average $=53.7 \pm 2.6$ and medium $=55 ; \mathrm{p}=0.000$, MannWhitney). An inverse correlation was observed between age and the performance of the participants on the BBS (Spearman $=-0.473$, $\mathrm{p}=0.000)$. The average age of the elderly did not vary according to gender $(\mathrm{p}=0.135)$.
Association between performance of the elderly on the BBS and the following variables: visual acuity, TUG, FES-I Brazil e VFO

The majority of the elderly presented a high performance on the total score of the BBS. Because of this, it was decided to separately verify the association of the items 08,13 and 14 of the scale (reaching forward with the arms extended, standing with one foot forward, and standing on one foot) which showed greater variability. These three items were associated with the variables TUG and FES-I-Brazil.

Association between visual acuity and performance of the elderly on the BBS

With relation to visual acuity, the associations were performed according to the vision of the better eye and a significant difference was observed on the BBS. Elderly with better visual acuity presented higher mediums on the balance scale (table 2). 
Table 2 - Association between the performance of the elderly on the Berg balance scale and the alterations presented in visual acuity. Belo Horizonte, MG, 2007. ( $\mathrm{N}=139)$

\begin{tabular}{lccccccc}
\hline & $\mathrm{N}$ & Average & $\begin{array}{c}\text { Standard } \\
\text { Deviation }\end{array}$ & Minimum & Average & Max & P value \\
\hline VA in the best eye & & & & & & & \\
Normal & 54 & 53.2 & 2.6 & 47.0 & 54.0 & 56.0 & 0.013 \\
Light & 72 & 52.0 & 3.4 & 38.0 & 52.0 & 56.0 & \\
Moderate/Severe & 13 & 49.6 & 4.9 & 39.0 & 49.0 & 56.0 & \\
\hline
\end{tabular}

Correlation between the performance of the participants on the BBS and the Timed Up and Go (TUG) test

An inverse correlation between the TUG and the total score of the BBS test was found $(C C=-0.528 ; p=0.000$, Pearson). The longer it took the participants to do the TUG, the lower the total BBS score was and visa-versa. The performance of the participants of the study on items 08,13 and 14 of the BBS and on the TUG was also verified (table 3 ). The three items of the balance scale showed a statistically significant association with the TUG (item 08, $\mathrm{p}=0.007$; item 13, $\mathrm{p}=0.001$ e item $14, \mathrm{p}=0.00$, KruskalWallis), demonstrating that, in this sample, the worse the performance on each item of BBS, the more time was spent to do the TUG.

Table 3 - Association between the performance of the elderly on the TUG and the items 8, 13 and 14 of the Berg balance scale. Belo Horizonte, MG, 2007. ( $\mathrm{N}=139)$

\begin{tabular}{lccccccc}
\hline & $\mathrm{N}$ & Average & $\begin{array}{c}\text { Standard } \\
\text { Deviation }\end{array}$ & Min. & Average & Max. & P value \\
\hline Berg-08 & & & & & & & \\
2 or 3 & 32 & 13.38 & 4.72 & 8.06 & 12.39 & 30.69 & $\mathbf{0 . 0 0 7 *}$ \\
4 & 107 & 11.08 & 2.08 & 6.85 & 10.81 & 16.31 & \\
Berg-13 & & & & & & & \\
0 or 1 & 50 & 12.77 & 4.13 & 7.53 & 12.21 & 30.69 & $\mathbf{0 . 0 0 1 *}$ \\
2 or 3 & 30 & 11.82 & 1.93 & 9.24 & 11.27 & 16.78 & \\
4 & 59 & 10.52 & 1.85 & 6.85 & 10.22 & 14.41 & \\
Berg-14 & & & & & & & \\
0 or 1 & 51 & 12.89 & 3.83 & 7.96 & 12.00 & 30.69 & $\mathbf{0 . 0 0 0 *}$ \\
2 or 3 & 42 & 11.38 & 2.14 & 7.53 & 11.14 & 16.09 & \\
4 & 46 & 10.41 & 2.14 & 6.85 & 10.05 & 17.66 & \\
\hline
\end{tabular}


Correlation between the performance of the participants on the BBS the Falls Efficacy Scale International (FES-I-Brazil)

The better the performance of the elderly on the total score of the BBS, the lower the total points were on the FES - in other words, the lesser the preoccupation with the possibility of falling $(\mathrm{CC}=-0.355, \mathrm{p}=0.000$, Pearson).
The association of the performance of the participants on items 08,13 and 14 of the BBS and the performance on the FES-I-Brazil were assessed through the nonparametric KruskalWallis test. The three items of the balance scale showed significant associations with the total FES score (item 08, $\mathrm{p}=0.004$; item $13, \mathrm{p}=0.015$; item $14, \mathrm{p}=0.010$ ), as shown in table 4 .

Table 4 - Association between the performance of the elderly on the FES-I-Brasil and on the items 8, 13 and 14 of the Berg balance scale. Belo Horizonte, MG, 2007. (N=139).

\begin{tabular}{lllcccccc}
\hline & & $\mathrm{n}$ & Average & $\begin{array}{c}\text { Standard } \\
\text { deviation }\end{array}$ & Minimum & Average & Maximum & P value \\
\hline Berg-08 & 2 or 3 & 32 & 27 & 7 & 16 & 27 & 44 & $\mathbf{0 . 0 0 \boldsymbol { H } ^ { * }}$ \\
& 4 & 107 & 23 & 6 & 16 & 21 & 48 & \\
Berg-13 & 0 or 1 & 50 & 26 & 8 & 16 & 24 & 48 & $\mathbf{0 . 0 1 5 ^ { * }}$ \\
& 2 or 3 & 30 & 23 & 5 & 16 & 21 & 42 & \\
& 4 & 59 & 23 & 6 & 16 & 21 & 40 & \\
Berg-14 & 0 or 1 & 51 & 26 & 7 & 16 & 24 & 44 & $\mathbf{0 . 0 1 0}$ \\
& 2 or 3 & 42 & 24 & 7 & 16 & 23 & 48 & \\
& 4 & 46 & 22 & 6 & 16 & 20 & 42 & \\
\hline
\end{tabular}

Correlation between the performance of the elderly on the total score of the BBS and the Visual Function Questionnaire (VFQ)

The results showed that no significant correlation could be observed between the performance of the participants on the BBS and on each of the variables of the VFQ (CC $=0.096$; $\mathrm{p}=0.259$, Pearson).

\section{Multivariate Regression}

Analysis of the multivariate regression between the BBS and the variables: gender, age, visual acuity, VFQ, FES-I-Brazil and number of medicines used. The regression analysis explained a $32.8 \%$ variance in the dependent variable (Berg).
The final equation was: $\operatorname{Berg}=71.203-0.245 \mathrm{x}$ Age +1.416 x Gender - 0.082 x FES .

\section{DISCUSSION}

Cataracts are the main cause of blindness in the world, being responsible for around $50 \%$ of the 50 million cases. ${ }^{6}$ In Brazil, estimates point to 2 to 3 new cases of visual acuity equal to or less than 0.5 in the best eye, due to senile cataract, for every thousand inhabitants. ${ }^{6}$ In this study, the elderly presented visual acuity between 0.5 and 0.3 , comprising a majority of women, fact that was also evident in other cataract studies in Brazil. ${ }^{22}$ Silva (2005), in a study among the elderly in Ouro Preto, state of Minas Gerais, 
found an association between dependence for the performance of daily life activities with visual alterations, with having female gender and with being older than 70 years old, in the research sample. It is important to point out the feminization process of old age. ${ }^{23}$ In Brazil, in 1995, for every 100 women 60 years old or more, there were 81 men of the same age. Not only health problems, but also social and economic problems of the elderly mostly pertain to old women, who live more than men. ${ }^{1}$

The control of equilibrium of the human body is regulated be the integration of three different systems: the somatosensory, the vestibular and the visual systems. The role of visual information in the control of balance has been documented by literature. ${ }^{24-27}$ Studies that use strength platforms to measure postural oscillation associated with individuals with poor vision showed that the lessening of visual information can reduce the postural stability in $50 \%$. This instability can be aggravated, mainly when associated with alterations of the somatosensory and vestibular systems. ${ }^{24-27}$

It is important to point out that the elderly, when undergoing tests in laboratories, may have alterations in their physical performance due to the emotional stress caused by an artificial environment. Despite several studies that associated visual deficit with precarious postural control, ${ }^{3-5}$ there are few studies assessing balance by functional measurements.

In the research sample, the BBS, considered to have adequate psychometric measurements and being widely used in research for assessment of balance in the elderly, presented a ceiling effect for the performance of the elderly in the global score. These results may be explained by the fact that the original scale was elaborated to assess frail old individuals and who had already presented some kind of alteration of balance. ${ }^{18,28}$ The participants of this study, despite having a diagnosis of cataract, were members of the community and were independent. The control of balance is multifactorial. The elderly, having visual deficit due to cataracts, possibly developed other compensatory mechanisms in order to perform their daily functional activities. However, some items proposed by the BBS item 08: reaching forward, 13: standing with one foot forward (tandem posture) and 14: one-foot support -, were proven to be more appropriate for detecting alterations in functional balance in the research sample. Berg et al. (1992) reported that these three items are the most difficult of the scale for the elderly. ${ }^{28}$ These items were the most sensitive for the research sample, showing that the active elderly with light alterations of balance need more difficult and more specific items for the assessment of functional balance.

The results of the study showed that there was a significant correlation between the decrease of visual acuity and the performance of the elderly on the BBS. Elderly patients with worse visual acuity presented a worse performance on the total score of the BBS, proving what has been observed in clinical practice - visual alterations generate a negative impact on functional performance.

Lee \& Scudds, in a cross-sectional study with 66 elderly (age 69-94 years) at a rehabilitation hospital, found an association between the total score of the BBS and the decrease of visual acuity. ${ }^{12}$ Elderly with no visual deficit showed an average on the BBS of $50.73 \pm 3.41$; light visual deficit, 45.55 \pm 6.85 , and moderate visual deficit, $38.59 \pm 8.31$. The averages of the total score of the scale were worse than the results found in this study. The use of the BBS on hospitalized elderly patients, differently than the sample of this study, which was composed of elderly patients of the community, contributed to these findings. Other studies found similar associations between visual deficit and alterations of functional balance in the elderly, although other functional tests were applied: Performance Oriented Mobility Assessment (POMA) and the Tinetti balance test. ${ }^{29,30}$

A significant moderate inverse correlation was found between the performance of the elderly on the total score of the BBS and the TUG, indicating that the better the performance 
of the elderly on the tests of balance, less time was spent to perform the TUG. As expected, this data supports the studies of Podsiadlo \& Richardson (1991) and Berg et al. (1992), who also found a moderate to high correlation in these tests among the community elderly. ${ }^{28}$

When we analyzed the items of greatest impact of the BBS (items: 08, 13 and 14) separately, we observed that the TUG varied significantly. These items were the most sensitive and appropriate for the research sample (item 08: $\mathrm{p}=0.007 ; 13: \mathrm{p}=0.001 ; 14: \mathrm{p}=0.000)$. According to Bohannon (2006), although the TUG is widely used in the last years, its normative reference values have not been well established, mainly for populations with visual deficit, where confounding variables may be present. ${ }^{31}$ This author also suggests that the cut off points for the interpretation of the TUG should be done according to the stratification of the sample by age groups. In the present study, the sample was not stratified by age group, which may have interfered in the results.

Fear of falling is associated with decline in physical and functional performance, in the ability to perform daily life activities, in alterations of balance and in the gait of the elderly. ${ }^{15,32}$ These authors suggest that efficacy in the control of balance in relation to falls, assessed by specific scales, would be able to evaluate the best manner of performance of the elderly, when compared to subjective and dichotomic questions about fear of falling. The activities of FES-I, that caused a greater preoccupation in relation to the possibility of falls among the elderly were those that demanded a high functional level (items 11, 14, 07, 15 and 04). This is in agreement with the sample of this study composed by elderly patients from the community, showing independence in their daily life activities, in which $35.3 \%$ of the subjects regularly practiced some kind of physical activity.

The Pearson correlation coefficient between the total score of the BBS and the total score of the FES-I-Brazil was equal to -0.355 ( $\mathrm{p}=0.000)$. These results indicated a significant inverse correlation, but which was weak using these assessment tools. The better the performance on the BBS, the less preoccupation with the possibility of falling, as assessed by the FES-IBrazil, there was. It is also important to point out that the fear of falling or the reduction of selfsufficiency is of a multifactorial etiology, making it hard to establish or determine the factors that can provoke this process. ${ }^{14,15}$

This study did not find correlation between the BBS and the assessment tool for functional vision $-\mathrm{VFQ}$ (Pearson $=0.096 ; \mathrm{p}=0.259)$. Despite the VFQ having domains that involve daily life activities and dependence; these are always focused on the difficulty of vision and not of balance.

To explore the nature of the relations between the BBS and the other variables involved in the study, and to identify which of them had greater impact on the balance of the elderly, the multivariate regression analysis was used.

The results showed that age, gender and FES-I were the variables associated with balance problems assessed by the BBS. Although the model reached the presupposition for its use, only $32,8 \%$ of the variability of the responses can be explained by this model, classified as moderate.

Balance, mobility, functional status and fear of falling are variables that suffer multifactorial influences, and thus, vision is not always the only or the main cause of these alterations. ${ }^{30}$ The age factor can be a variable that contributes to these functional alterations, since the literature reports that difficulties related to visual function and physical performance increase with age. ${ }^{33}$

\section{CONCLUSION}

This study found significant weak or moderate associations between balance assessed by the BBS, visual acuity, TUG and the FES-IBrazil. In the regression analysis, age proved to be one of the variables most strongly associated with alterations in Berg's functional balance. 


\section{REFERENCES}

1. Chaimowicz F. Health of Brazilian elderly just before of the 21st century: current problems, forecasts and alternatives. Rev Saude Publica 1997 Apr;31(2):184-200.

2. Salive ME, Guralnik J, Glynn RJ, Christen W, Wallace RB, Ostfeld AM. Association of visual impairment with mobility and physical function. J Am Geriatr Soc 1994 Mar;42(3):287-92.

3. Lamourex E, et. al. The relationship between visual function, duration and main causes of vision loss and falls in older people with low vision. Graefes Arch Clin Exp Ophthalmol 2010 Apr;248(4):527-33.

4. Lord SR, Smith ST, Menant JC. Vision and falls in older people: risk factors and intervention strategies. Clin Geriatr Med 2010 Nov;26(4):569-81.

5. Dillon CF, Gu Q, Hoffman HJ, Ko CW. Vision, hearing, balance, and sensory impairment in Americans aged 70 years and over: United States, 1999-2006. NCHS Data Brief 2010 Apr;(31):1-8.

6. Zacharias LC, Graziano RM, Oliveira BFT, Hatanaka M, Cresta FB, Kara-José N. A campanha da catarata atrai pacientes da clínica privada. Arquivos Brasileiros Oftalmológicos 2002;65:557-61.

7. Black A, Wood J. Vision and falls. Clin Exp Optom 2005 Julhy;88(4):212-22.

8. Schwartz S, Segal O, Barkana Y, Schwesig R, Avni I, Morad Y. The effect of cataract surgery on postural control. Invest Ophthalmol Vis Sci 2005 Mar;46(3):920-4.

9. Daubney ME, Culham EG. Lower-extremity muscle force and balance performance in adults aged 65 years and older. Phys Ther 1999 Dec;79(12):1177-85.

10. Maeda A, Nakamura K, Otomo A, Higuchi S, Motohashi Y. Body support effect on standing balance in the visually impaired elderly. Arch Phys Med Rehabil 1998 Aug;79(8):994-7.

11. Stones MJ, Kozma A. Balance and age in the sighted and blind. Arch Phys Med Rehabil 1987 Feb;68(2):85-9.

12. Lee HK, Scudds RJ. Comparison of balance in older people with and without visual impairment. Age Ageing 2003 Nov;32(6):643-9.

13. Bloem BR, Steijns JA, Smits-Engelsman BC. An update on falls. Curr Opin Neurol 2003 Feb;16(1):15-26.

14. Legters K. Fear of falling. Phys Ther 2002 Mar;82(3):264-72.

15. Powell LE, Myers AM. The Activities-specific Balance Confidence (ABC) Scale. J Gerontol A Biol Sci Med Sci 1995 Jan;50A(1):M28-34.

16. Jack CI, Smith T, Neoh C, Lye M, McGalliard JN. Prevalence of low vision in elderly patients admitted to an acute geriatric unit in Liverpool: elderly people who fall are more likely to have low vision. Gerontology 995;41(5):280-5.

17. Keller BK, Morton JL, Thomas VS, Potter JF. The effect of visual and hearing impairments on functional status. J Am Geriatr Soc 1999 Nov;47(11):1319-25.

18. Miyamoto ST, Lombardi Junior I, Berg KO, Ramos LR, Natour J. Brazilian version of the Berg balance scale. Braz J Med Biol Res 2004 Sep;37(9):1411-21.

19. Podsiadlo D, Richardson S. The timed "Up \& Go": a test of basic functional mobility for frail elderly persons. J Am Geriatr Soc 1991 Feb;39(2):142-8.

20. Ferraz EVAP, Lima CA, Cella W, Arieta CEL. Adaptation of the questionnaire of the assessment of life quality for application with patients with cataracts. Arq Bras Oftalmol 2002;65:293-8.

21. Camargos FFO. Adaptação transcultural e avaliação das propriedades psicométricas da Falls Efficacy Scale-International: um instrumento para avaliar medo de cair em idosos. [tese] Belo Horizonte: UFMG; 2007.

22. Oliveira RSCS, Temporini ER, Kara-José N, Carricondo PC, Kara-José AC. Perceptions of patients about cataract. Clinics 2005;60(6):455-60.

23. Silva ALA. Avaliação multidimensional de uma população de idosos residentes na cidade de Ouro Preto, Minas Gerais, Brasil. [ dissertação]. Belo Horizonte: UFMG; 2005.

24. Anand V, Buckley J, Scally A, Elliott DB. The effect of refractive blur on postural stability. Ophthalmic Physiol Opt 2002 Nov;22(6):528-34.

25. Anand V, Buckley JG, Scally A, Elliott DB. Postural stability in the elderly during sensory perturbations and dual tasking: the influence of refractive blur. Invest Ophthalmol Vis Sci 2003 Jul;44(7):2885-91.

26. Lord SR, Menz HB. Visual contributions to postural stability in older adults. Gerontology 2000 NovDec;46(6):306-10.

27. Teasdale N, Simoneau M. Attentional demands for postural control: the effects of aging and sensory reintegration. Gait Posture 2001 Dec;14(3):203-10.

28. Berg KO, Maki BE, Williams JI, Holliday PJ, WoodDauphinee SL. Clinical and laboratory measures of postural balance in an elderly population. Arch Phys Med Rehabil 1992 Nov;73(11):1073-80.

29. Huang M, Burgess R, Weber M, Greenwald N. Performance of balance impaired elders on three balance tests under two visual conditions. J Geriatr Phys Ther 2006;29(1):5-9. 
30. Owsley C, McGwin G, Jr. Association between visual attention and mobility in older adults. J Am Geriatr Soc 2004 Nov;52(11):1901-6.

31. Bohannon RW. Reference values for the timed up and go test: a descriptive meta-analysis. J Geriatr Phys Ther 2006;29(2):64-8.
32. Tinetti ME, Richman D, Powell L. Falls efficacy as a measure of fear of falling. J Gerontol 1990 Nov;45(6):P239-43.

33. West CG, Gildengorin G, Haegerstrom-Portnoy G, Schneck ME, Lott L, Brabyn JA. Is vision function related to physical functional ability in older adults? J Am Geriatr Soc 2002 Jan;50(1):136-45.

Recebido: $11 / 4 / 2011$

Revisado: 08/11/2011

Aprovado: 05/12/2011 